\title{
Microcomputerized clinical and research laboratories in psychiatric inpatient settings
}

\author{
WILL SPAULDING, W. JEFF CRINEAN, and THOMAS MARTIN \\ University of Nebraska, Lincoln, Nebraska 68508
}

\begin{abstract}
Microcomputers have become increasingly useful in clinical settings, performing functions ranging from test administration to composition of narrative reports. They may in the near future be involved in therapeutic procedures. Clinicians and researchers have begun to wonder whether a microcomputer can take over a wide range of functions in clinical psychiatric settings, becoming a versatile and cost-effective tool. This paper describes the development of a comprehensive system for research and clinical data management on a psychiatric inpatient unit. The core of the system is an Apple II-Plus microcomputer equipped with PASCAL, standard peripherals, and an inexpensive custom interface. The system has met the current data management needs of the unit, and its expandability allows planning of assessmentand treatment-related research.
\end{abstract}

Psychiatric inpatient units have for many years been rich resources for research in experimental psychopathology and related topics. Recently, on-line computers have gained a central role in this research, for several reasons. The first is a proliferation of laboratory paradigms being used to study abnormal behavior. The psychological deficits that are suspected to be instrumental in causing the behavior patterns characteristic of schizophrenia and similar disorders range from deficient preattentive visual feature processing to inflexible conceptual processing. A computer-controlled laboratory is advantageous in the study of these deficits and, in fact, necessary in some cases (see Spaulding \& Space, 1979).

A second advantage of computers in the psychopathology laboratory is that they remove an otherwise unavoidable social interaction factor from testing procedures. Schizophrenics are notoriously sensitive to social stimulation, to the degree that their performance can be quantitatively influenced simply by the physical proximity of the experimenter. Thus, computercontrolled experiments subtract a potentially significant confounding factor from the experimental setting (see Cromwell \& Spaulding, 1979).

A third advantage is that computers can perform clinically relevant functions. This is important even to basic researchers, because it allows a research project to provide useful services. This in turn improves the coop-

This project was supported in part by the UN-L Research Council, by NIH Biomedical Research Support Grant RR07055, and by the Lincoln Regional Center, Nebraska Department of Public Institutions. Special acknowledgment is made to the Lincoln Regional Center administration and to the clinical staff of the LRC Comprehensive Care Service. eration of clinical personnel, upon whom the researchers must often depend for data collection. The clinical abilities of computers range from psychological test interpretation to composition of interview-based narrative reports (see Hedlund, Vieweg, Wood, Cho, Evenson, Hickman, \& Holland, 1981; Johnson, 1981; Sidowski, Johnson, \& Williams, 1980; Spaulding, Hargrove, Crinean, \& Martin, 1981).

Recently, the potential of computers in clinical psychiatric settings has accelerated even more. Various researchers have reported success in directly modifying the attentional and cognitive deficits characteristic of schizophrenia with learning-based precedures. Some of these deficits are those that are best measured with online tests. Clinically oriented researchers are beginning to have visions of "Atari-Age" psychotherapy for schizophrenics wherein attentional and cognitive deficits are modified with video game formats controlled by computers.

While computers are becoming increasingly versatile and useful research tools in psychiatric settings, the need for computerization of standard clinical procedures in those settings is also increasing. This is due to two trends: growing recognition that the behavior of severely disturbed patients must be assessed at several levels of functioning, from psychophysiological to social, and a nationwide movement toward better documentation and accountability in mental health institutions. For both researchers and clinicians, these trends lead to a need to manage large amounts of diverse types of data.

The converging trends in computer technology, psychopathology, and mental health policy raise an intriguing question: Are specialized computers to become pivotal multipurpose instruments in psychiatric settings, as ubiquitous as $\mathrm{X}$-ray machines and resusci- 
tators are in medical settings? There is little doubt that computers are performing an increasing number of functions previously impossible or done by humans at far greater expense. The question is rather one of economics. Not only must the computer be cost-effective, but its initial cost must be within reach of the typical mental health agency budget. This is a significant constraint. A computer system that costs much more than $\$ 15,000$ would be beyond the means of many agencies, regardless of how soon the system would pay for itself in human work hours. Timesharing is not a solution, partly because of its continuing cost and partly because some applications require real-time functions in millisecond time frames.

Obviously, only a microcomputer would be within these constraints. The question then becomes: can a microcomputer do enough data management, special assessment, and treatment procedures to justify itself in a typical psychiatiric setting?

For 3 years, our research group has been exploring various clinical and research applications of the Apple IIPlus microcomputer. We have become convinced that virtually any routine data management task in a psychiatric setting could be handled by the Apple II-Plus. Until recently, however, we had not attempted to use the microcomputer to do special laboratory procedures and manage a comprehensive data system in a working clinical research setting.

In the spring of 1981, our research group was invited to participate in development of a new psychosocial treatment unit at a local state hospital. The goal of the unit was to be the habilitation of chronically institutionalized patients through behaviorally oriented and empirically validated treatment. Our group was to develop a data system that could efficiently manage all data relevant to the year-long treatment of the units' 35 patients. Also, hopefully, the data system would serve as the foundation for a variety of research projects on innovative assessment and treatment methods. The invitation appeared to be an opportunity to test the practicality of a comprehensive microcomputerized laboratory and data system.

\section{DESIGN PREREQUISITES}

Comprehensive data management on an inpatient psychosocial treatment unit poses significant challenges, especially to researchers armed only with an Apple IIPlus computer. The first challenge is the sheer quantity of data to be collected. By the time the units' treatment program was fully developed, it included 25 different therapy groups and rehabilitation classes. These range from social skills training to gestalt therapy to "music appreciation groups." Each patient has a "behavior program," an individualized social contingency management plan targeting specific behaviors for modification. Most patients are expected to undergo "drug titration," an enlightened but complex procedure whereby the lowest necessary dose of antipsychotic drugs is determined by systematically varying dosages over time. The unit established a "level system" for managing the various ward privileges used in the contingency management programs, and patients are expected to be constantly fluctuating from one level to another.

A complicating factor is the individualization of treatment programs. No two patients could be expected to be attending the same groups, taking the same drug doses, on the same behavior program, and so on. Each patient represents a unique combination of clinically relevant variables.

Finally, there would be considerable variance in output needs. Data summaries would predictably be needed for semiannual case reviews and monthly staff meetings. However, the unit is also structured so that a patient's treatment team might call a meeting virtually on a moment's notice to make tactical adjustments in that patient's program. Data summaries would therefore also have to be available at a moment's notice.

\section{CLINICAL MEASURES}

The first step in computerizing the unit's clinical data was to design a data form to characterize patients' performance in all the therapy groups, classes, and workshops available in the treatment program. The form is completed weekly by all group leaders for each patient assigned to the group. Data on the form includes patients' attendance, a six-item scale of specific behaviors exhibited during the group meeting, and a 10-point scale reflecting overall progress in the group. Descriptors for the 10-point progress scale were developed separately for each group. For example, descriptors for the social skills group focus on patients' acquisition of new social skills during the group meeting, whereas descriptors for group psychotherapy focus on the quality of interactions with other patients in the group. Thus, the single group/class/workshop form allows comparison across treatment modalities in three spheres: attendance, behavior in group, and overall progress. The number of forms produced per patient per week is determined by the number of groups prescribed in each patient's treatment plan.

Patient's behavior outside formal treatment is assessed with two measures. One is the 30-item Nurses' Observational Scale for Inpatient Evaluation (NOSIE-30; Honigfeld, 1974), which reflects social behavior on the living unit. The second is the Inpatient Multidimensional Psychiatric Scale (IMPS; Lorr \& Klett, 1966), an 89. item interview-based behavior checklist. Both the IMPS and the NOSIE-30 can be administered as frequently as necessary.

The group/class/workshop form, the NOSIE-30, and the IMPS together provide a week-to-week evaluation of patients' social behavior that is adequate for monitoring most short-term changes. However, social behavior is only one of the several levels of functioning that are 
relevant to the assessment and treatment of pervasively disordered patients. For that reason, we designed into our system the capacity to generate data on psychophysiology, attention, and cognition.

For cognitive and attentional evaluation, we assembled a battery of tests frequently used in experimental psychopathological research. The battery generates 10 attentional and cognitive measures whose psychometric properties in clinical populations are relatively well known. The measures range from preattentive feature processing (measured by a backward-masking procedure) to size estimation to concept formation. The tests are all administered, scored, and recorded by the microcomputer.

At the molar end of the cognitive level of functioning are processes associated with attributions and selfperceptions. These can be of importance in pervasively disordered patients, to the degree that they orient the individual to a deviant, dependent, institutional lifestyle. We chose three measures of attributional processes that seem particularly relevant: the Rotter I-E Locus of Control Scale (Hill \& Bale, 1980), the Mental Health Locus of Origins Scale (Hill \& Bale, 1980), and the Motivator-Hygiene Scale (Herzberg \& Hamlin, 1960). All are questionnaire-type scales that can be individually administered.

The psychophysiological factors most relevant to pervasively disordered patients are psychotropic drugs and their therapeutic and nontherapeutic effects. We found the "physician's orders" section of the patients' charts to be a convenient format for computer input, so no special data collection form was needed. Therapeutic drug effects are best measured by behavior scales like the NOSIE-30 and the IMPS. Nontherapeutic drug effects do require special assessment. We provided for that with the Extrapyramidal Side Effects Scale (Simpson \& Angus, 1970) and the Abbreviated Tardive Dyskinesia Scale (Simpson, Lee, Zoubok, \& Gardos, 1979). Both are checklists that can be filled out by a physician or nurse during a 10 - to 15 -min examination.

During the patient's 1st week on the unit, an initial assessment is done. The ward psychologist administers the IMPS, two nursing staff members administer a NOSIE-30, the ward psychiatrist administers the drug side-effect scales, and the patient is seen in the laboratory for the attentional, cognitive, and attributional assessments. After the initial week, the amount of data generated by each patient varies greatly. At minimum, a NOSIE-30 is done weekly. Usually, the patient attends only one or two group activities for several weeks. However, within 1 or 2 months, the patient may be involved in 8-10 different groups, each generating a weekly data form. During periods when a specific treatment intervention is being evaluated, the entire admission protocol may be repeated weekly. This, combined with group/class/workshop data, could amount to over 300 data points per patient per week.

\section{HARDWARE AND LOW-LEVEL SOFTWARE}

Our system is built around an Apple II-Plus microcomputer with dual disk drives, a PASCAL language card, a SONY color TV, a dc Hayes modem, and an IDC printer. The only nonstandard peripheral device is a subject response console that was designed and built in our laboratory. The console provides response buttons and keys used in the cognitive and attentional tests. It interfaces with the microcomputer through the Apple's game-paddle connectors. The microcomputer, response console, and supporting assembly-level programs are described in detail in a previous paper (Spaulding et al., 1981).

\section{HIGH-LEVEL SOFTWARE AND THE FILING SYSTEM}

Four PASCAL programs constitute the laboratory's software system. One program collects, stores, and cross-indexes clinical data. Most of the data come to the laboratory on various forms and score sheets. The program provides interactive displays by which a clerk enters the data from the forms through the keyboard.

Two important factors, drug and behavior modification regimens, cannot be easily translated into quantitative data. In these cases, descriptions of the regimens' starting dates and therapeutic goals can be stored in the data file as text. Information for entry is taken directly from the patient's chart.

The second program administers the attentional and cognitive tests and stores the results in the data fields.

The third program provides all the output functions that are used by clinical staff. Data from each measure are reduced and configured for interpretation and comparison. Sample printouts for a hypothetical patient are included in the appendix to this paper. As can be seen in the sample printouts, the data are arranged to facilitate interpretation of changes over time. For the IMPS and NOSIE-30, the subscale scores can be quickly transferred by hand to graphic profile sheets that are standard components of those measures. The profiles provide both a graphic representation of the subtest scores and standardized transformations of the raw subtest scores.

The fourth program is used when a patient's initial data file becomes full. The program prints out all the data in the file as an archival record and prepares the file for transfer to long-term storage. The file can then be transferred by the modem to the University Computer Center to be stored on tape. The archived data on mainframe tape accumulate to provide a data bank for research and program evaluation.

The programs reside on a "command" disk, which normally operates in the first disk drive. The data are stored on a second disk in the second drive as they are input. Each disk contains one patient's data. The data input program initializes and formats each patient's 
disk and, after the first data disk has been filled and archived, initializes and catalogs a second disk.

For security reasons, no identifying information is stored on the data disks. Patients' names and other identifiers are stored on a separate disk (the "master" disk) that indexes the identifiers with code numbers. To access a particular patient's data, the operator must have the "master" disk and must know the command sequence for obtaining the code number that identifies that patient's disk.

Except for the security precaution, all the programs are menu driven and user friendly. After a minimal amount of familiarization with the system, any clinical staff member can input data or obtain a printout by responding to prompts or instructions. The programs are also error-proof. All information entered into the system must be entered twice, so that error-checking routines can check for discrepancies.

To guard against disk failure, a "backup" disk is maintained for every data disk. The data input program prompts the operator when the backup is to be updated and then prompts every step of the procedure. Error checks guard against insertion of the wrong disk and other possible operator errors.

The key to managing the large amount of individualized data is the PASCAL "Case" statement used to define a record type (this is a little known but extremely powerful feature of PASCAL). The "Case" statement allows the data input program to declare a "Record" of unspecified "Type." The "Type" is specified later, when the data are input.

The system treats the various clinical measures as "Records" of different "Types." When the operator enters a NOSIE-30 or some other set of data, two entries are made on the disk. The data are added to a data file as a "Record," and a corresponding entry is made in a separate index file. The index entry includes a code that identifies the "Type" of "Record" entered, the date on which the data were collected, and file pointers to locate the record in the data file. When the data are being retrieved for output, the "Records" in the data file can be accessed by scanning the index file for "Records" of specified "Types" whose input dates lie within a specified time period. The file pointers for that index entry are then read, and the corresponding "Record" in the data file is retrieved.

This method of scanning allows great flexibility in data entry. Data can be entered at the convenience of the operator, without regard to date or type, because order of input is irrelevant to retrieval. The index scan is done very quickly; little time is lost by repeatedly scanning the index for a particular date, incrementing the data after each scan.

The "Case" defining "Type" strategy also allows new clinical measures to be added to the system with minimal program modification. To add a new measure, a new "Type" is added to the list of alternatives in the "Case" list and assigned an identifying code. It then remains only to write interactive subprograms for col- lecting the data and for configuring them for output. The program already contains routines that put any "Record" of any "Type" and its index entry into the data files.

\section{LIMITATIONS, REVISIONS, AND FUTURE DEVELOPMENT}

The system has been operational since June 1982 . So far, it seems to be taking over the units' comprehensive data management as planned.

The main limitation of the system is the amount of space available for on-line data storage. The patient's data disk fills up in about 6 weeks, after which a new disk must be initialized. This is not currently a problem because the archival printout provides all needed information from the old disk. However, as new clinical or research measures are added to the system, the time required to fill the disk will inevitably shorten. The system would become awkward to use if disks had to be archived every week or 2 .

One source of the space problem is the PASCAL "Case" statement in "Type" definitions. When several "Type" alternatives are induced in one "Record," space must be allocated in all cases for the largest "Type." In other words, when a 100-item measure is included with a 10 -item measure, the 10 -item measure must be allocated as much space as the 100 -item measure. This space inefficiency is a tradeoff for high-level programming simplicity.

A possible solution for the problem would be to strategically separate groups of "Types" according to their length and frequency of collection. Short but frequently collected measures could thereby be stored in smaller spaces. In our system, the group/class/workshop measure is a good candidate for separate filing. It contains only 10 items, but it takes as much space as the 85-item IMPS. Since several group/class/workshop forms per patient per week came to the laboratory, the data take up a large amount of disk space. However, the present system will need to become considerably more awkward before the time, effort, and increased program complexity involved in a change would be justified.

The flexibility and expandability of PASCAL more than compensate for its limitations, in our experience (the general advantages of PASCAL in microcomputerized psychopathology laboratories has been detailed elsewhere; see Spaulding \& Space, 1979). It is doubtful that the present application could have been accomplished at all in BASIC or a comparable language. It is particularly important that individual measures can be added or eliminated from the system with minimal effort. It is not at all clear which measures will turn out to be the most useful in this particular setting, and there is no reason to believe there would be much generalization across settings. There is much trial and error ahead for clinicians and researchers who endeavor to establish comprehensive data-based assessment and treatment programs in psychiatric settings. The flexibility of PASCAL is especially relevant to that state of affairs. 
Our strategy for future system development is oriented toward developing more valid measures of performance in a broader range of patients' levels of functioning. Of particular relevance is the psychophysiological level. In our present system, psychophysiological measures are limited to factors associated with psychotropic drug regimens. The psychopathology literature abounds with direct measures of potential usefulness, but all require sophisticated and expensive hardware.

We are currently experimenting with the Biocomp 2000 , a psychophysiological monitoring device manufactured by the Biofeedback Research Institute of Los Angeles, California. The system costs about $\$ 7,000$, software included. The Biocomp interfaces with the Apple II through the Apple game connector. It provides four channels of standard psychophysiological measures in any combination. A valuable feature of the Biocomp is that it communicates with the Apple with infrared telemetry. This eliminates wire leads and permits patients to be monitored from a distance in naturalistic settings. Unfortunately, the Biocomp was designed for biofeedback therapy and its software is in BASIC. Nevertheless, with no modifications, we can do biofeedback therapy and naturalistic recording of psychophysiological responsivity, using the Biocomp's built-in data filing system. We are now modifying the software to be compatible with our PASCAL-based data system.

Our success so far suggests that a low-cost microcomputer can perform comprehensive data management in a psychiatric inpatient setting. In addition, microcomputerbased laboratories in such settings may provide specialized assessment and treatment that could not be done with more conventional means. The possibilities at this point seem worthy of pursuit. The "Atari Age" of mental health may be upon us.

\section{REFERENCES}

Cromwell, R., \& Spaulding, W. A microprocessor-based psychopathology laboratory: 1. Why bother? Behavior Research Methods \& Instrumentation, 1979, 11, 241-242.

Hedlund, J. L., VieweG, B. W., Wood, J. B., Cho, D. W., Evenson, R. C., Hickman, C. V., \& Holland, R. A. (Eds.). Computers in mental health. Washington, D.C: Superintendent of Documents, U.S. Government Printing Office, 1981.

Herzberg, F., \& Hamlin, R. A motivation-hygiene concept of mental health. Mental Hygiene, 1960, 45, 394-401.

Hill, D., \& Bale, R. Development of the Mental Health Locus of Control and Mental Health Locus of Origin Scales. Journal of Personality Assessment, 1980, 44, 148-156.

HoNigFeLD, B. NOSIE-30: History and current status of its use in pharmacopsychiatric research. In P. Pichot (Ed.), Modern problems in pharmacopsychiatry (Vol, 7): Psychological measurements in pharmacology. Karger: Basel, 1974.

Johnson, J. H. (Ed.). Special issue: Computer technology and methodology in clinical psychology, psychiatry, and behavioral medicine. Behavior Research Methods \& Instrumentation, 1981, 13, 389-629.

LORR, M., \& KLETT, C. Manual: Inpatient multidimensional psychiatric scale (rev. ed.). Palo Alto, Calif: Consulting Psychologists Press, 1966.

Sidowski, J. B., Johnson, J. H., \& Williams, T. A. (Eds.). Technology in mental health care delivery systems. Norwood, N.J: Ablex, 1980.

Simpson, G., \& Angus, J. A rating scale for extrapyramidal side effects. Acta Psychiatrica Scandinavica, 1970, 212, 11. (Supplement)

Simpson, G., Lee, J., Zoubok, B., \& Gardos, G. A rating scale for tardive dyskinesia. Psychopharmacology, 1979, 64, 171-179.

Spaulding, W., Hargrove, D., Crinean, J., \& Martin, T. A microprocessor-based laboratory for psychopathology research in rural settings. Behavior Research Methods \& Instrumentation, 1981, 13, 616-623.

Spauldina, W., \& Space, L. A microprocessor-based psychopathology laboratory: II. Research goals and design prerequisites. Behavior Research Methods \& Instrumentation, $1979,11,243-246$.

Appendix

Clinical Output on a Hypothetical Patient

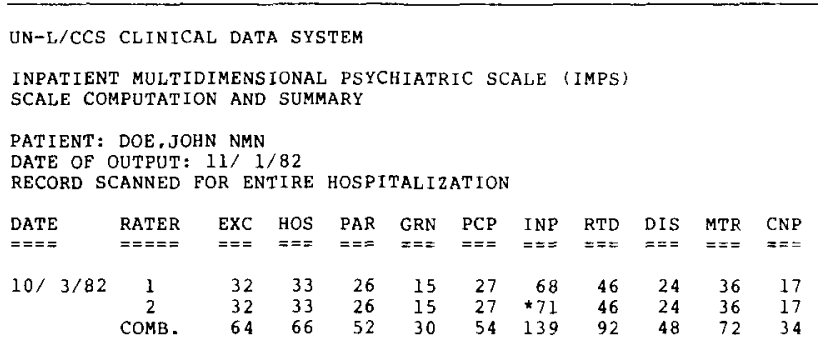

*PRORATED; $"-1$ INDICATES MISSING VALUES

OUTPUT COMPLETED.
UN-L/CCS CLINICAL DATA SYSTEM

DRUG-RELATED SYMPTOMS INVENTORY

PATIENT: DOE, JOHN NMN

DATE OF OUTPUT: $11 / 1 / 82$

RECORD SCANNED FOR ENTIRE HOSPITALIZATION

I. EXTRAPYRAMIDAL SIDE EFFECTS SCALE

\begin{tabular}{|c|c|c|c|c|}
\hline $\begin{array}{l}\text { DATE } \\
====\end{array}$ & $\begin{array}{l}\text { SLIGHT } \\
======\end{array}$ & $\begin{array}{l}\text { MODERATE } \\
=======\end{array}$ & $\begin{array}{l}\text { MARKED } \\
==== \pm=\end{array}$ & $\begin{array}{l}\text { EXTREME } \\
==== \pm=\end{array}$ \\
\hline $10 / 2 / 82$ & $\begin{array}{l}\text { GAIT } \\
\text { WRIST RIGID } \\
\text { TREMOR }\end{array}$ & $\begin{array}{l}\text { ARM DROP } \\
\text { LEG RIGID } \\
\text { SALIVATION }\end{array}$ & $\begin{array}{l}\text { SHLDR RIGID } \\
\text { HEAD DROP }\end{array}$ & $\begin{array}{l}\text { ELBOW RIGID } \\
\text { GABELLA TAF }\end{array}$ \\
\hline
\end{tabular}

EPS INDEX: 23.0

$\begin{array}{llll}\text { II. TARDIVE DYSKINESIA SYMPTOMS SCALE } & \\ \text { DATE } & \text { SLIGHT } & \text { MODERATE } & \\ \text { MARKED } & \text { EXTREME }\end{array}$

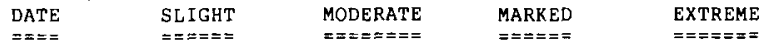

$\begin{array}{lllll}10 / 2 / 82 & \text { CHEWING } & \text { BONBON SIGN } & \text { TONGUE PROT } & \text { FACIAL TREM } \\ \text { TRUNK IDEO } & \text { TOPSION } & \text { ROCKING } & \text { AXIAL HYPRK }\end{array}$ STAMPING FOOT MVMNTS HAND MVMNTS EXTMTY IDEO ARATHESIA BODY IDEO

IDEOPATHIC SYMPTOMS :

NECK/TRUNK: SHOULDER SPASMS

EXTREMITIES: BACK TWIST

EXTREMITIES: BACK TWIST

TARDIVE DYSKINESIA INDEX: * 63.8 
UN-L/CCS CLINICAL DATA SYSTEM

\section{ATTRIBUTIONAL ASSESSMENT}

PATIENT: DOE, JOHN NMN

DATE OF OUTPUT: $11 / 1 / 82$

RECORD SCANNED FOR ENTIRE HOSPITALIZATION

I. LOCUS OF CONTROL

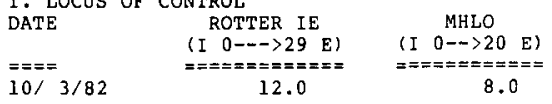

I . MOTIVATOR-HYGIENE SCALE

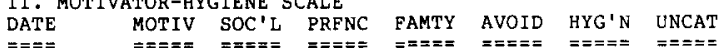

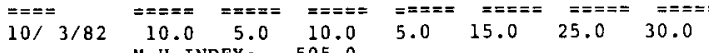
M-H INDEX: $\quad 505.0$

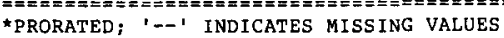

OUTPUT COMPLETED.

UN-L/CCS CLINICAL DATA SYSTEM

NURSES OBSERVATION SCALE FOR INPATIENT EVALUATION (NOSIE-30) SCALE COMPUTATION AND SUMMARY (73082)

PATIENT: DOE,JOHN NMN

DATE OF OUTPUT: $11 / 1 / 82$

RECORD RETROSCANNED FROM 10/31/82 FOR 4 WEEKS

\begin{tabular}{|c|c|c|c|c|c|c|c|c|}
\hline $\begin{array}{l}\text { DATE } \\
====\end{array}$ & $\begin{array}{l}\text { RATER } \\
x= \pm==\end{array}$ & $\begin{array}{l}\text { COM } \\
===\end{array}$ & $\begin{array}{l}\text { INT } \\
==E\end{array}$ & $\begin{array}{l}\text { NEA } \\
\mathbf{x = x}\end{array}$ & $\begin{array}{l}\text { I RR } \\
===\end{array}$ & $\begin{array}{l}\text { PSY } \\
===\end{array}$ & $\begin{array}{l}\text { RET } \\
===\end{array}$ & $\begin{array}{l}\text { TOTAL } \\
== \pm=\mathbf{x}\end{array}$ \\
\hline $10 / 28 / 82$ & $\begin{array}{c}1 \\
2 \\
\text { COHB. }\end{array}$ & $\begin{array}{l}14.0 \\
12.0 \\
26.0\end{array}$ & $\begin{array}{r}8.0 \\
10.0 \\
18.0\end{array}$ & $\begin{array}{r}8.0 \\
7.0 \\
15.0\end{array}$ & $\begin{array}{c}8.8^{*} \\
10.0 \\
18.8\end{array}$ & $\begin{array}{r}12.0 \\
7.5 \\
19.5\end{array}$ & $\begin{array}{r}6.0 \\
5.0 \\
11.0\end{array}$ & 105.7 \\
\hline $10 / 21 / 82$ & $\begin{array}{c}1 \\
2 \\
\text { СОМB. }\end{array}$ & $\begin{array}{l}14.0 \\
12.0 \\
26.0\end{array}$ & $\begin{array}{r}6.0 \\
10.0 \\
16.0\end{array}$ & $\begin{array}{r}9.0 \\
8.0 \\
17.0\end{array}$ & $\begin{array}{r}9.0 \\
14.0 \\
23.0\end{array}$ & $\begin{array}{l}10.5 \\
10.5 \\
21.0\end{array}$ & $\begin{array}{r}4.0 \\
7.0 \\
11.0\end{array}$ & 100.0 \\
\hline $10 / 14 / 82$ & $\begin{array}{c}1 \\
2 \\
\text { Сомв. }\end{array}$ & $\begin{array}{c}8.0 \\
11.2^{\star} \\
19.2\end{array}$ & $\begin{array}{l}10.0 \\
11.0 \\
21.0\end{array}$ & $\begin{array}{l}7.0 \\
12.0 \\
19.0\end{array}$ & $\begin{array}{r}13.0 \\
9.0 \\
22.0\end{array}$ & $\begin{array}{l}13.5 \\
15.0 \\
28.5\end{array}$ & $\begin{array}{r}4.0 \\
9.0 \\
13.0\end{array}$ & 91.8 \\
\hline $10 / 7 / 82$ & $\begin{array}{c}1 \\
2 \\
\text { сомв. }\end{array}$ & $\begin{array}{r}8.0 \\
7.0 \\
15.0\end{array}$ & $\begin{array}{l}12.0 \\
15.0 \\
27.0\end{array}$ & $\begin{array}{l}14.0 \\
11.0 \\
25.0\end{array}$ & $\begin{array}{l}18.0 \\
14.0 \\
32.0\end{array}$ & $\begin{array}{l}21.0 \\
19.5 \\
40.5\end{array}$ & $\begin{array}{r}8.0 \\
9.0 \\
17.0\end{array}$ & 73.5 \\
\hline
\end{tabular}

$=x==== \pm=E z=r=E x=$
OUTPUT COMPLETED.
UN-L/CCS CLINICAL DATA SYSTEM

GROUP/CLASS PERFORMANCE AND ATTENDENCE SUMMARY (71382)

PATIENT: DOE, JOHN NMN

DATE OF OUTPUT: $11 / 1 / 82$

RECORD RETROSCANNED FROM 10/31/82 FOR 5 WEEKS.

\begin{tabular}{cllll} 
(WEEK OF) & GROUP & SCHED & ACTUAL & PERFMNC \\
DATE & CODE & ATTEND & ATTEND & SCALE \\
\hline
\end{tabular}

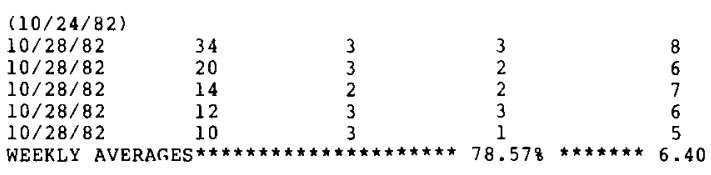

$(10 / 17 / 82)$

$\begin{array}{lcccc}(10 / 17 / 82) & & & & \\ 10 / 21 / 82 & 34 & 3 & 3 & 4 \\ 10 / 21 / 82 & 20 & 2 & 1 & 4 \\ 10 / 21 / 82 & 15 & 3 & 2 & 6 \\ 10 / 21 / 82 & 12 & 2 & 2 & 7 \\ 10 / 21 / 82 & 10 & 2 & 1 & 6 \\ \text { WEEKLY AVERAGES } * \star \star \star \star \star \star \star \star \star \star \star \star \star \star \star \star \star \star * \star * & 75.008 \star \star \star \star \star \star \star & 5.40\end{array}$

$(10 / 10 / 82)$

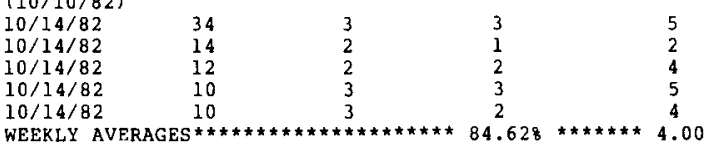

$(10 / 3 / 82)$

$10 / 7 / 82$

$10 / 7 / 82$

$10 / 7 / 82$

$10 / 7 / 82$
$10 / 7 / 82$

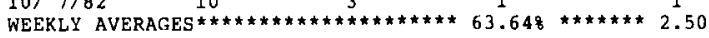

$(9 / 26 / 82)$

(NO DATA FOUND FOR THIS PERIOD)

$(9 / 19 / 82)$

(NO DATA FOUND FOR THIS PERIOD)

$(9 / 12 / 82)$

(NO DATA FOUND FOR THIS PERIOD)

SCAN WENT TO END OF RECORD FOR THIS DATA

$======x== \pm=====$
OUTPUT COMPLETED. 